\title{
Prospects and challenges of multimedia approach to tourism mapping in Nigeria: a case of wildlife parks mapping
}

\begin{abstract}
Nigeria has a vast array of both natural and cultural tourist attractions. The country's tourism industry, however, remains grossly underdeveloped, and the tourism resources are largely untapped. Hence, the tourism sector of the economy is yet to contribute significantly to the national Gross Domestic Product (GDP). One major factor that is responsible for the nation's current lacklustre performance of the tourism sector is the poor state of tourism packaging and promotion, which, amongst other things is caused by the lack of appropriate tourist maps. Tourism mapping is a key component of tourism planning, development, promotion and management. For Nigeria to drastically and significantly improve the fortunes of her tourism sector, the production, circulation and use of accurate, current and comprehensive tourist maps and atlases must be vigorously pursued. To ensure sustainable tourism mapping and in line with global best practices, the country needs to adopt a Geoinformation technology-based, Internet-compatible multimedia cartographic approach.

The author of this paper, therefore, examines the current state of tourism industry and tourism mapping in Nigeria. Some of the hiccups to tourism mapping in the country are identified. The implications of the present poor state of tourism mapping on tourism planning, development, promotion and management in the country are briefly considered. The author makes a strong case for the adoption of a multimedia cartographic approach to tourism mapping in Nigeria. A case of mapping wildlife parks in Nigeria is presented to demonstrate the prospects of effective multimedia tourism mapping of the country. Furthermore, the author identifies and discusses various existing resources in the country that could be harnessed for efficient and sustainable production, distribution and use of multimedia tourist maps/atlases, using Geographical Information Technologies (GIT). Some potential challenges to effective GIT-based tourism mapping in the country as well as how such challenges could be overcome, are equally discussed. Similarly, a model for Web-based, multimedia tourism mapping using GIT is presented. With clear vision, the right policy instrument, mandate, legislation, funding and coordination in place, the current challenges to effective and sustainable tourism mapping in Nigeria can easily be surmounted.
\end{abstract}

Keywords: Tourism mapping, multimedia cartography, Nigeria, wildlife parks

\section{Introduction}

Nigeria has numerous and diverse potential tourist attractions. Most of the tourist attractions, however, are largely and unexplored. Thus, tourism remains an untapped goldmine in Nigeria. Despite the numerous exquisite potential tourist attractions that abound in the country, the contribution of this sector to the country's GDP at present is embarrassingly low.

Quite a number of factors could be held responsible for the current underdeveloped state of the tourism sector in Nigeria. One of such factors is poor packaging and publicity of tourism, especially for the consumption of the international community. In particular, tourism mapping, which is an essential component of tourism promotion and development, is very much lagging behind. There is a glaring absence of a roadmap for the production of Guide Maps for publicizing and promoting Nigeria's tourism endowments; and this is seriously affecting the development of the tourism industry in the country. The pivotal role of maps in tourism management has not been sufficiently realized and recognized by the official operators and managers of the tourism and hospitality industry in the country. As a consequence, the 
tempo and degree of tourism mapping in the country remain abysmally low. Yet the shortage of appropriate tourist maps and atlases of $\mathrm{Ni}$ geria continues to constitute a huge impediment to the growth and development of that sector of the nation's economy and culture.

Given the central role of tourism mapping in the sustainable development and management of tourism, this paper presses on the urgent need to vigorously, comprehensively and effectively map and disseminate to the global community useful information about the tourist attractions in Nigeria. But achieving efficient tourism mapping in Nigeria would require a drastic paradigm shift. Attention must necessarily move away from the traditional mapping workflow. A more pragmatic, innovative and robust technical mapping approach must be adopted. This calls for fully embracing Geographic Information Technologies (GIT). Hence, this paper ideates and discusses a GIT-based, Internet-compatible multimedia cartographic approach for the creation and use of tourism maps and atlases of Nigeria. The paper briefly $\mathrm{x}$-rays the tourism mapping in Nigeria using wildlife parks mapping as a case study. The paper also reviews the available opportunities in the country for effective multimedia tourism mapping, as well as the possible challenges to GIT-based multimedia tourism mapping. Lastly, the paper signals the way forward by making some insightful suggestions as well as presenting a model detailing the components of a multimedia tourism mapping system that could help galvanize, guide and expediate action towards achieving sustainable tourism mapping in Nigeria.

\section{Materials and methodology}

\subsection{Study area}

Geographically, Nigeria is located within the Gulf of Guinea Large Marine Ecosystem (GCLME), which is an arm of the Atlantic Ocean, in western Africa. It is located approximately within latitudes $4^{\circ} \mathrm{N}$ and $14^{\circ} \mathrm{N}$, and longitudes $2^{\circ} \mathrm{E}$ and $15^{\circ} \mathrm{E}$ (fig. 1). The country is bordered on the north by both Niger Republic

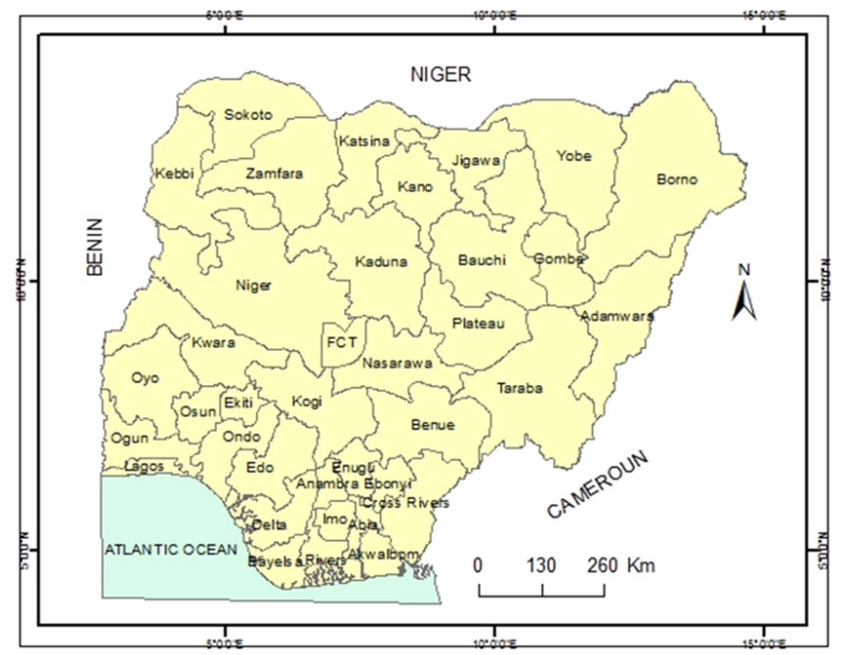

Fig. 1. Administrative divisions of Nigeria

tourism industry in Nigeria, the role of maps in tourism development, the state of tourism mapping in the country, and the need for GIT-based Internet-compatible multimedia tourism mapping in Nigeria. Furthermore, the paper demonstrates the possibility of digital multimedia and Chad Republic, on the east by Republic of Cameroun, on the south by the Atlantic Ocean, and on the west by Benin Republic.

Nigeria is a country of immense diversity physically, culturally, socially and otherwise. In particular, the country has a rich tourism sector; 
the country is endowed with a vast diversity of tourist attractions. There are both natural and cultural features and events that can easily attract the interest of a potential tourist. For instance, there are scenic and breath-taking natural attractions such as waterfalls, hills, mountains, caves, cold/warm springs, rainforest, mangrove gallery, savannah, wildlife sanctuary, lakes, and so on. Similarly, various spectacular cultural events such as exhilarating traditional festivals, scintillating masquerade displays, exciting boat regatta, colourful carnivals, mesmerizing traditional dances, thrilling durbar, and so on, abound in the country. Many of the tourist attractions in the country are either full UNESCO Heritage Sites or itemized on the UNESCO World Heritage Sites' tentative list.

Perhaps, largescale international tourism in Nigeria started with the country's hosting in 1977 of the first ever World Black Festival of Arts and Culture, otherwise known as FESTAC ' 77. This followed the official commissioning in 1976 of the Nigeria Tourism Board (NTB), now Nigeria Tourism Development Corporation (NTDC), which was inaugurated in 1992. The inauguration of the then NTB and the FESTAC ' 77 helped to place Nigeria on the global tourism map. Furthermore, in a bid to promote tourism development and growth in the country and thus derive her fair share of the boom in this industry, the country formulated a National Tourism Policy (NTP) in 1990. The main thrust of government policy on tourism, is to make Nigeria the ultimate tourism destination in Africa, thereby generate foreign exchange, encourage even development, promote tourism-based rural enterprises, generate employment and accelerate rural-urban integration and cultural exchange. In 2006 the Nigerian Tourism Development Master Plan was launched. Subsequently, some other bold initiatives were also taken by government to diversify the country's mono-cultural economy through promotion of tourism (O.O. Ayeni 2012). Such other measures include the establishment of the National Institute for Hospitality and Tourism (NIHOTOUR), in Baganda, Kano State, and the National Travel Bureau (NTB) - which is a tour operating company of NTDC; the production and adoption of a tourism master plan; and the inauguration of the National Tourism Council with the President of the country as Chairman.
Tourism coupled with hospitality, arts and culture, has immense potential to play a pivotal role in the nation's quest for economic recovery, growth and development. Given the country's rich bio-diversity and ecosystem, traditional cultural diversity, historical cities and arts and crafts, Nigeria's tourism industry offers great potential for economic growth. Unfortunately, Nigeria's tourism sector has been in a somewhat hibernation state. As a consequence, Nigeria is still very far from significantly harnessing the benefits of the tourism industry as a source of jobs for the teeming unemployed youths in the society, revenue generation, and access to better living conditions for the citizens. Less than three per cent of tourists visiting Africa annually choose Nigeria as their tourism destinations. Currently, tourism and hospitality account for only about 4.7 per cent of the country's GDP.

Certain factors are responsible for the poor performance of the Nigerian tourism subsector. One major constraint to tourism development in the country is the undue focus on the oil and gas sector to the near neglect of other sectors, especially tourism. There is a glaring nonchalant attitude towards the tourism industry by both the public and private sectors; this has obviously led to a general lack of proper management of tourism in the country.

Another key challenge to tourism development in Nigeria is weak and defective tourism branding and promotion. The infrastructure necessary for tourism promotion is grossly inadequate. Most of the required tourism advertisement tools (e.g. maps, websites, radio/TV jingles, tourism and tour guides, newsletters, etc.) are either non-existent or largely lacking. This leads to shortage of relevant tourist data and access to information. In the tourism industry, availability of and access to reliable data and statistics plays a significant role in planning and decision making. Quite often, both domestic and foreign tourists find it difficult getting useful information on tourism attractions and activities in Nigeria. Moreover, Nigerian tour operators and travel agents are fond of promoting more of outbound tourism than inbound. Thus, the domestic tourism resources of the country are less marketed to the outside world. As a consequence, potential inbound tourists to the country are hardly aware of the existence of the tourism assets and are, therefore, not encouraged to visit the country. 
The tourism industry in Nigeria (like some other sectors) suffers from shortage of safe and enabling environment for investors to come in and do business in the country. The country's infrastructural deficiency (as exemplified by poor electricity, roads, and water quality) coupled with insecurity in parts of the country significantly affects tourism activities. Moreover, there is often undue official bureaucracy that makes it somewhat stressful for investors or travelers to Nigeria to do so with ease.

Although concerted efforts have been, and are still being, made to address the above identified challenges to tourism industry development in Nigeria, a lot more still needs to be done. One area that must be urgently looked into is mapping for tourism development, promotion and management. The poor state of tourism mapping in the country is seriously affecting every facet of the tourism industry in the country.

\subsection{Methodology}

A two-pronged approach was adopted in this study. One approach involved fieldwork while the order involved extensive desktop review. The fieldwork was undertaken to gather relevant data on each of the wildlife parks in the Nigeria. In this wise, a Global Positioning System (GPS) was used to obtain the geographical coordinates of each of the parks, while a digital camera was used to acquire photographs of some of the wildlife species. Similarly, relevant spatial information on the geographical extent of the parks were derived from existing 1:50,000 topographic map series covering various parts of the country. In addition, attribute or descriptive information on the wildlife parks such as the wildlife species as well as availability of accommodation and some other facilities in each park were equally collected. The ArcGIS 10.3.1 software package by Environmental Systems Research Institute (ESRI) was used to create and manage a GIS spatial database and the associated attribute database of the wildlife parks. GIS was also used to manipulate, query, map and visualize information on the location, distribution, extent and names of the parks. More so, GIS was used to generate and hyperlink maps of the parks with some image (photographs) and textual (attribute) information.
An extensive desktop review was undertaken to ascertain the existing resources (spatial data infrastructure, institutions, legislation, projects and personnel) necessary for effective, comprehensive and sustained GIS-based multimedia tourism mapping in Nigeria. Likewise, through the desktop review, the various potential challenges that could affect elaborate multimedia cartographic mapping of Nigeria's tourism resources were identified. On the basis of both the field work and multimedia cartographic mapping of wildlife parks carried out as well as the desktop review conducted, a model for robust GIS-based multimedia tourism mapping in Nigeria was presented and briefly discussed.

\section{Literature review}

\subsection{Maps and tourism development}

The role of maps as an important instrument in tourism development, promotion and management cannot be overemphasized. A geo-tourist map combines the most evident geological/geomorphological aspects with basic tourist information, such as parking places, footpaths, picnic areas, overnight-stay places, etc. (D. Castaldini 2008). A typical tourist map will contain information on certain main features including but not limited to administrative boundaries (of states and the country), road and rail networks, international and domestic airports and airstrips, relief and nature (highlands, lowlands and water bodies), forest and game reserves, cultural and historical sites, recreation and parks, zoos, museums, settlements (cities, towns, villages), hotels, entertainment centres, shopping malls, and so on.

Tourist map is one of the most important tools in promoting tourism (O.V. Eboy 2017). Maps are important tools for tourism destination guide and marketing. Map provides information on the existence, location, and distance between landscape features, such as tourist attractions, populated places, routes of travel, lodging and communication. Maps provide relevant general information to the tourist at a glance, which enables the tourist to travel intelligently, safely and with great expectation. Tourism mapping is important to provide guidance to tourists in identifying and finding the best tourism spots in the area. Tourism maps are 
also vital in developing the right and positive image of the natural and cultural landscape of a place amongst tourists, thus enabling tourists to appropriately reason spatially with respect to the areas to be visited.

To be useful, tourism maps need to be produced based on the appropriate aim and concept, and with the right tools. Moreover, the maps must be accurate, current and readily available for use. Inaccurate or poorly drawn tourist maps can mislead tourists. Similarly, absence or shortage of good tourist maps can keep potential tourists uninformed and lacking in information about the available tourist attractions in a place.

\subsection{Tourism mapping in Nigeria}

A general overview of tourism mapping in Nigeria is hereby presented. The status of tourism mapping in Nigeria is not as encouraging as one would have normally expected. There are very many opportunities for effective and efficient tourism mapping in the country. Nevertheless, the creation of tourist maps of Nigeria is yet to attain any enviable height. There is a huge market for tourism maps of Nigeria. Unfortunately, the appropriate tourist maps of the country are simply not available at the right quality and quantity.

The reasons for the wobbly state of tourism mapping in Nigeria have been aptly and concisely captured by N.O. Uluocha (2012, p. 183) thus:

"In the Nigerian context, tourism mapping has yet to receive the attention it so much deserves. Tourism mapping and the use of tourist maps have yet to be mainstreamed into the government's aim of developing and promoting the tourism industry. There has never been a comprehensive nationwide inventory and mapping of Nigeria's tourism resources. A look at the 1990 National Tourism Policy and the 2006 Nigerian Tourism Development Master Plan reveals a glaring lack of recognition of mapping and maps as instruments for effective integration of tourism development and management".

Though tourism mapping in Nigeria is relatively at a poor state, frantic efforts are currently being made, especially by private enterprises, to use modern geoinformation tools (digital car- tography, satellite imagery, GIS, GPS, etc.) as well information communication technologies (ICTs) to produce and distribute both analogue and digital (including multimedia) tourist maps of the country.

\subsection{The need for GIT-based multimedia tourism mapping in Nigeria}

Generally speaking, the need for Nigeria to leverage on Science, Technology and Innovation (STI) to build a knowledge-based economy cannot be overemphasized. In particular, if the poor state of tourism mapping in the country is to be dramatically and significantly improved upon, then adopting a multimedia tourism cartography powered by Geographical Information Technologies (GIT), is a must. Multimedia or hypermedia cartography (fig. 2) involves the

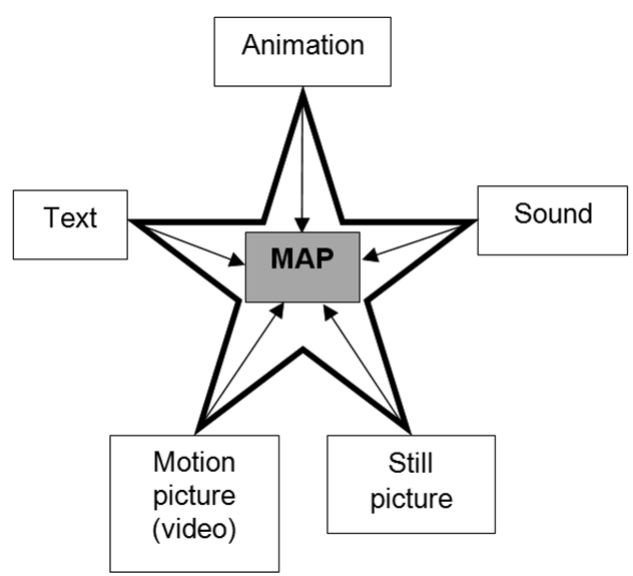

Fig. 2. Components of a multimedia cartography

use of a combination of maps, still pictures, motion pictures (videos), text document, sound, and computer animation to create a composite graphic display. The map forms the rallying point in multimedia cartography. Hence, multimedia cartography is predicated on the compelling notion that combining or integrating maps with other media (text, pictures, video, sound, etc.) will lead to more realistic representations of the world (M.P. Peterson, 1999). Simply put, digital multimedia cartography allows for interactive integration of maps with sound, 
text, animation, images (pictures and video), to get a better understanding of the mapped phenomena as a whole (M.J. Kraak and F.J. Ormeling 1998). Combining maps with some audio-visual elements boosts the capability of maps as exploratory, decision-making and communication tools (M.E. Ufuah 2006).

A major aim of multimedia tourism mapping is to produce maps that can easily be interpreted by tourists with even an average education and help them to understand the landscape of interest (D. Castaldini, 2008). Internet compatible GIS-based multimedia cartography is ideal for creating interactive tourism maps to market tourist destinations. Multimedia tourism atlas and tourism maps offer several advantages. Such maps show destinations in context, giving viewers a real sense of place and perspective. In other words, multimedia maps effectively connect geographical locations of tourist attractions to their actual images (photographs and videos) and descriptions of tour destinations, thereby giving viewers a sense of being there. Being interactive in nature, viewers can click interactive maps to get additional detail about any tourist attractions and points of interest such as waterfalls, cultural festival, hotels, etc. Thus, the interactive hypermedia atlas/maps would enable potential tourists to see and acquaint themselves with the tourism resources in a place before going there.

There is a palpable urgent need to fully adopt a GIT-based multimedia cartographic approach to shore up the state of tourism mapping in $\mathrm{Ni}$ geria. As noted earlier, tourism mapping in the country is generally in a poor state, and this is owing to a number of reasons, which have already been enunciated. As clearly pointed out, one of the major reasons for the lowly state of tourism mapping in the country is the widespread dependence on the old-fashioned, drudgery, time-consuming and less efficient analogue approach to mapping. Obviously, if the efficient and effective production and widespread use of tourist maps for tourism planning, development, promotion and management in Nigeria is to be achieved, then there is no other option than to fully embrace the digital geo-information technology-based mapping approach. A multimedia cartographic approach to tourism mapping in Nigeria is highly desirous to enable tourists get an advance feel of the sights and sounds of Nigeria; this will potentially arouse their interest to visit the country.

Nigeria needs to harness the immense technical and economic values of geospatial technologies and services. Geoinformation technologies are needed to map and disseminate accurate, timely and comprehensive information on a variety of tourism-related issues such as existing tourist attractions, their locations, morphology, distribution, condition, accessibility, and so on. Hence, powerful geospatial technologies such as digital cartography, remote sensing, GPS, and GIS are quite useful in the timely provision of the all-important geographical information needed to effectively develop, promote and manage the tourism sector (N.O. Uluocha 2004, T.I. Akukwe and C.J. Odum 2014).

The use of digital maps would definitely help to promote and encourage patronage of the tourism industry. Multimedia tourist maps have the potency for improving the knowledge, approbation, utilization and appraisal of tourist attractions. Besides, multimedia tourist atlas/maps can meet the research and educational needs of some public and private sectors. More so, the potential huge economic benefits of multimedia tourism mapping cannot be overlooked. The availability and use of digital tourism maps can reduce travel time, which can translate to a decrease in cost in monetary terms. For instance, the launch and use of digital Google map for location of street addresses reduced travel time in Nigeria by an average of eight per cent. In monetary terms, this reduced travel time alone saves Nigerians about 588 million US dollars a year.

Overall, Web-based multimedia mapping is beneficial in a number of ways including but not limited to cost effectiveness (it is less expensive to produce and distribute colour maps and other graphics through the Web than it is to print and distribute on paper); time-saving (maps and other spatial data on computer networks are delivered in a fraction of the time that was previously required); flexible and scalable Internet map implementation; high level of usability; and easy sharing of knowledge and information for decision making (N.O. Uluocha 2007). Some other potential benefits of the system include easy and quicker access to map data in both hard and soft copy form, quicker production of up-to-date atlas, ability to per- 
form analyses and make decision on map data in electronic form, easy updating, revision and rescaling of maps, enhanced opportunity to sensitize potential users who can have access to map data in digital form for display on their own personal computers (O.O. Ayeni 2012).

\section{Results and discussion}

The results of this study are presented and discussed in three parts namely, multimedia mapping of Wildlife Parks in Nigeria, prospects of multimedia tourism mapping in Nigeria, and challenges of multimedia tourism mapping in Nigeria.

\subsection{Multimedia mapping of wildlife parks in Nigeria}

To demonstrate the prospects of large-scale multimedia tourism mapping in Nigeria, information on wildlife parks in the country were collected and used. Nigeria has a total of eight national wildlife parks. The parks are Yankari, Okomu, Cross River (Oban Hills and Okwango sectors), Old Oyo, Kainji Lake (Borgu and Zuguma sectors), Gashaka Gumpt, Kamuku, and Chad Basin.

As mentioned in the methodology, the ArcGIS 10.3 software was used to create and manage the spatial and attribute databases of

Table 1. National wildlife parks in Nigeria

\begin{tabular}{|c|c|c|c|c|}
\hline Name Of Park & Location & Area & Coordinates & Accomodation \\
\hline $\begin{array}{l}\text { Old Oyo } \\
\text { National Park }\end{array}$ & Oyo State & $2,512 \mathrm{~km}^{2}$ & $\begin{array}{l}\text { 8.2500-9.0000N, } \\
3.5833-4.700 \mathrm{E}\end{array}$ & $\begin{array}{l}\text { Guest House within the park; } \\
\text { Hotels are within Oyo township } \\
\text { such as Labaiba Hotels }\end{array}$ \\
\hline $\begin{array}{l}\text { Cross River } \\
\text { National Park: } \\
\text { Oban Hills Sector }\end{array}$ & Cross River & $2,800 \mathrm{~km}^{2}$ & $5.4167 \mathrm{~N}, 8.5833 \mathrm{E}$ & $\begin{array}{l}\text { Kayang field station has simple } \\
\text { accommodation and guest houses } \\
\text { at Obudu. The Obudu Ranch Hotel }\end{array}$ \\
\hline $\begin{array}{l}\text { Okomu National } \\
\text { Park }\end{array}$ & Ondo State & $124 \mathrm{~km}^{2}$ & $6.4167 \mathrm{~N}, 5.4667 \mathrm{E}$ & $\begin{array}{l}\text { There is a rest house in the heart } \\
\text { of the National park; Two Bedrooms } \\
\text { at Arakhina town. }\end{array}$ \\
\hline $\begin{array}{l}\text { Gashaka Gumpti } \\
\text { National Park }\end{array}$ & $\begin{array}{l}\text { Adamawa } \\
\text { State }\end{array}$ & $6,670 \mathrm{~km}^{2}$ & $\begin{array}{l}6.9167-8.0833 \mathrm{~N} \\
11.1833-12.2167 \mathrm{E} \\
\end{array}$ & $\begin{array}{l}\text { Available at Serti or Gashaka } \\
\text { regions }\end{array}$ \\
\hline $\begin{array}{l}\text { Cross River } \\
\text { National Park: } \\
\text { Okwango Sector }\end{array}$ & Cross River & $920 \mathrm{~km}^{2}$ & $\begin{array}{l}6.0667-6.4833 \mathrm{~N} \\
9.000-9.4500 \mathrm{E}\end{array}$ & $\begin{array}{l}\text { Kayang field station has simple } \\
\text { accomodation and guest houses } \\
\text { at Obudu. The Obudu Ranch Hotel }\end{array}$ \\
\hline $\begin{array}{l}\text { Kanji Lake } \\
\text { National Park: } \\
\text { Zuguma Sector }\end{array}$ & Niger State & $5,341 \mathrm{~km}^{2}$ & \begin{tabular}{|l}
$9.6667-10.5000 \mathrm{~N}$ \\
$3.5000-5.8333 \mathrm{E}$
\end{tabular} & $\begin{array}{l}\text { Guest house in Olli camp and hotels } \\
\text { in Kanji town e.g. Kanji Motels }\end{array}$ \\
\hline $\begin{array}{l}\text { Kanji Lake } \\
\text { National Park: } \\
\text { Borgu Sector }\end{array}$ & Niger State & $5,341 \mathrm{~km}^{2}$ & $\begin{array}{l}9.6667-10.5000 \mathrm{~N} \\
3.5000-5.8333 \mathrm{E}\end{array}$ & $\begin{array}{l}\text { Guest house in Olli camp and hotels } \\
\text { in Kanji town e.g. Kanji Motels }\end{array}$ \\
\hline $\begin{array}{l}\text { Kamuku National } \\
\text { Park }\end{array}$ & $\begin{array}{l}\text { Kaduna } \\
\text { State }\end{array}$ & $1,127 \mathrm{~km}^{2}$ & $10.7500 \mathrm{~N}-11.0000 \mathrm{E}$ & $\begin{array}{l}\text { Guest house is within the park } \\
\text { region. Hotels are also present } \\
\text { within the area at easy reach }\end{array}$ \\
\hline $\begin{array}{l}\text { Yankari Nation } \\
\text { Park }\end{array}$ & Bauchi State & $2,244 \mathrm{~km}^{2}$ & $9.7500 \mathrm{~N}, 10.5000 \mathrm{E}$ & Bauchi Catering Rest House \\
\hline $\begin{array}{l}\text { Chad Basin } \\
\text { National Park: } \\
\text { Chingumi-Duguma } \\
\text { Sector }\end{array}$ & Borno State & $354 \mathrm{~km}^{2}$ & $\begin{array}{l}11.50-12.00 \mathrm{~N} \\
13.50-15.00 \mathrm{E}\end{array}$ & \\
\hline
\end{tabular}


national wildlife parks in Nigeria. Table 1 contains information on the name, location, area, geographic coordinates and availability of accommodation (for tourists) of each of the parks. GIS was used to manipulate, query and cartographically map and visualize information on the location, distribution, extent and names of the parks (fig. 3). More so, GIS was used to generated and hyperlink maps of the parks with some image (photographs) and textual information, as can be seen in figures 4-6. The list of wildlife species in each park, which

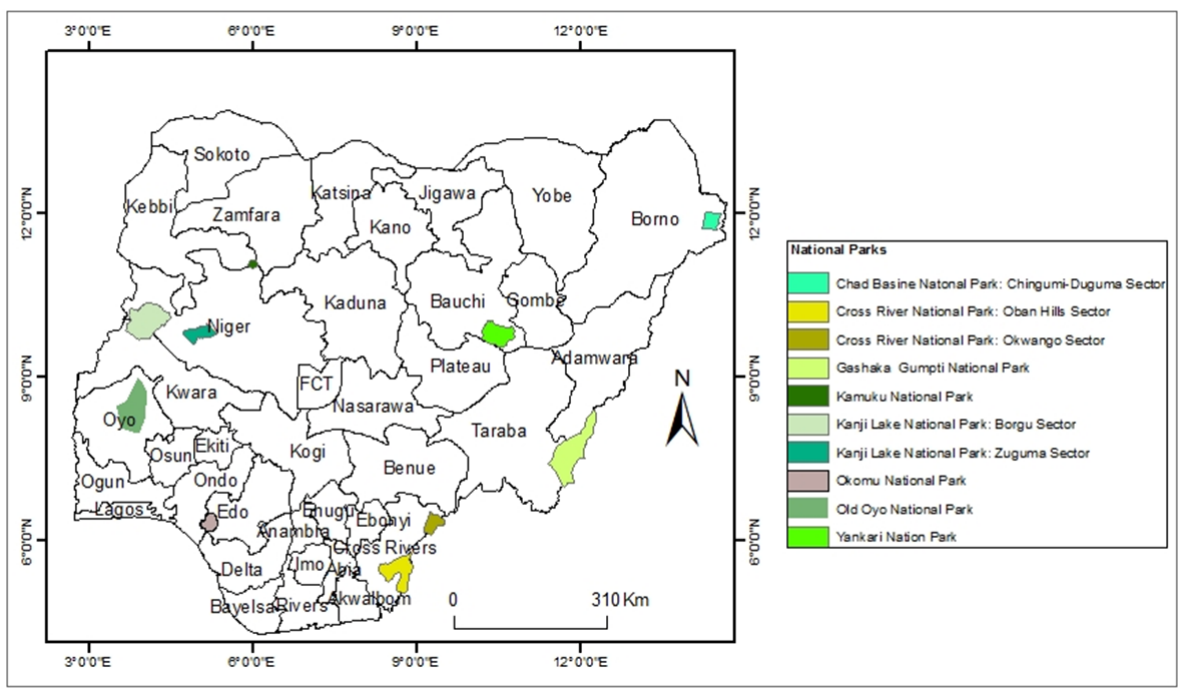

Fig. 3. National Wildlife Parks in Nigeria

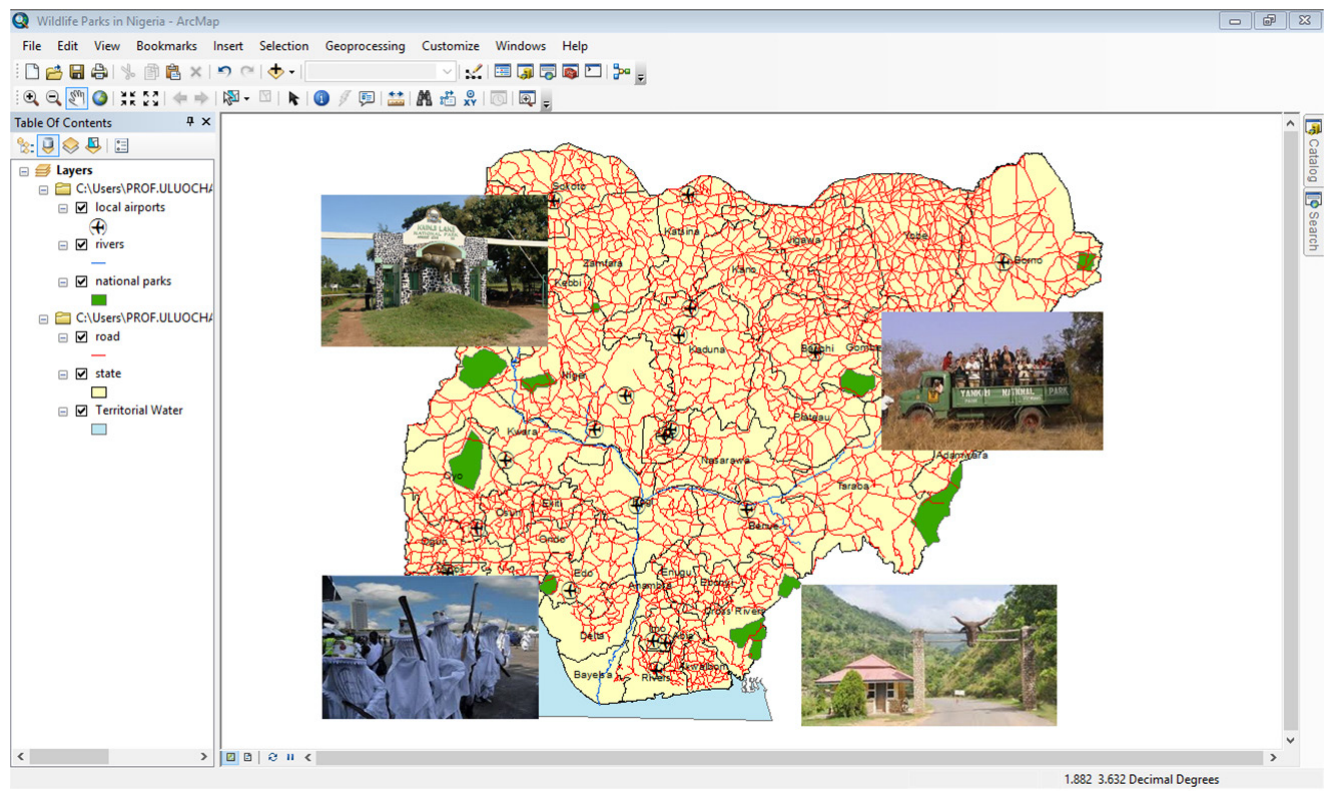

Fig. 4. Screenshot of a GIS tourist map of Nigeria hyperlinked with photos of some tourist attractions 


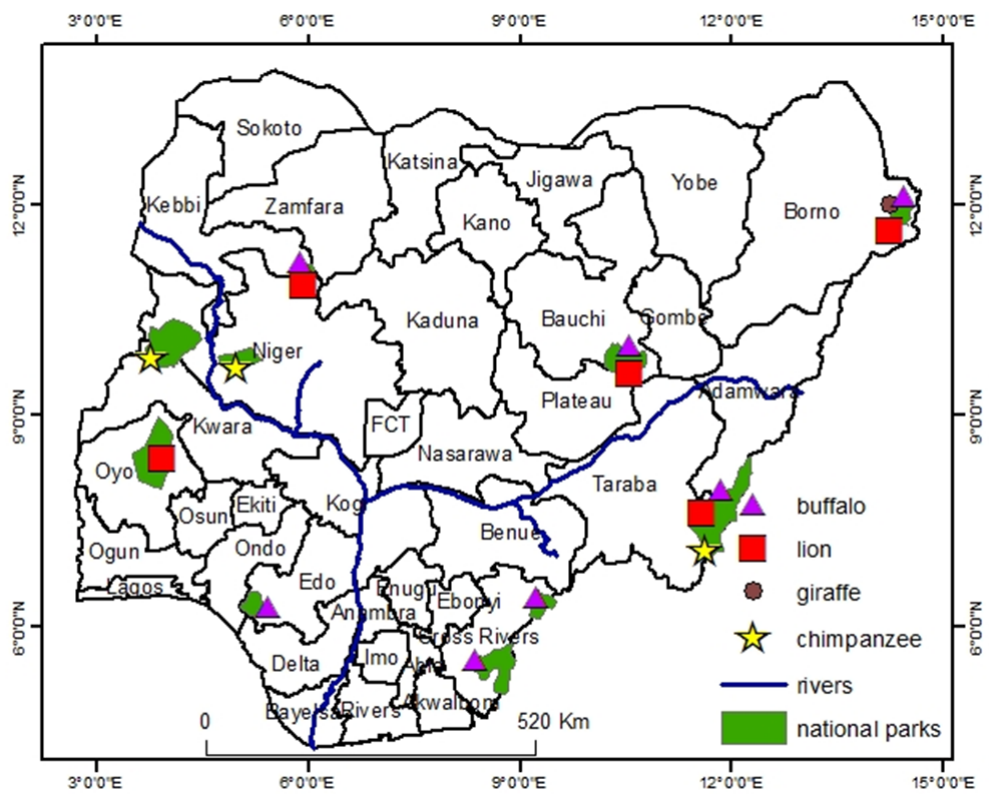

Fig. 5. Distribution of some wildlife species in Nigeria's wildlife parks

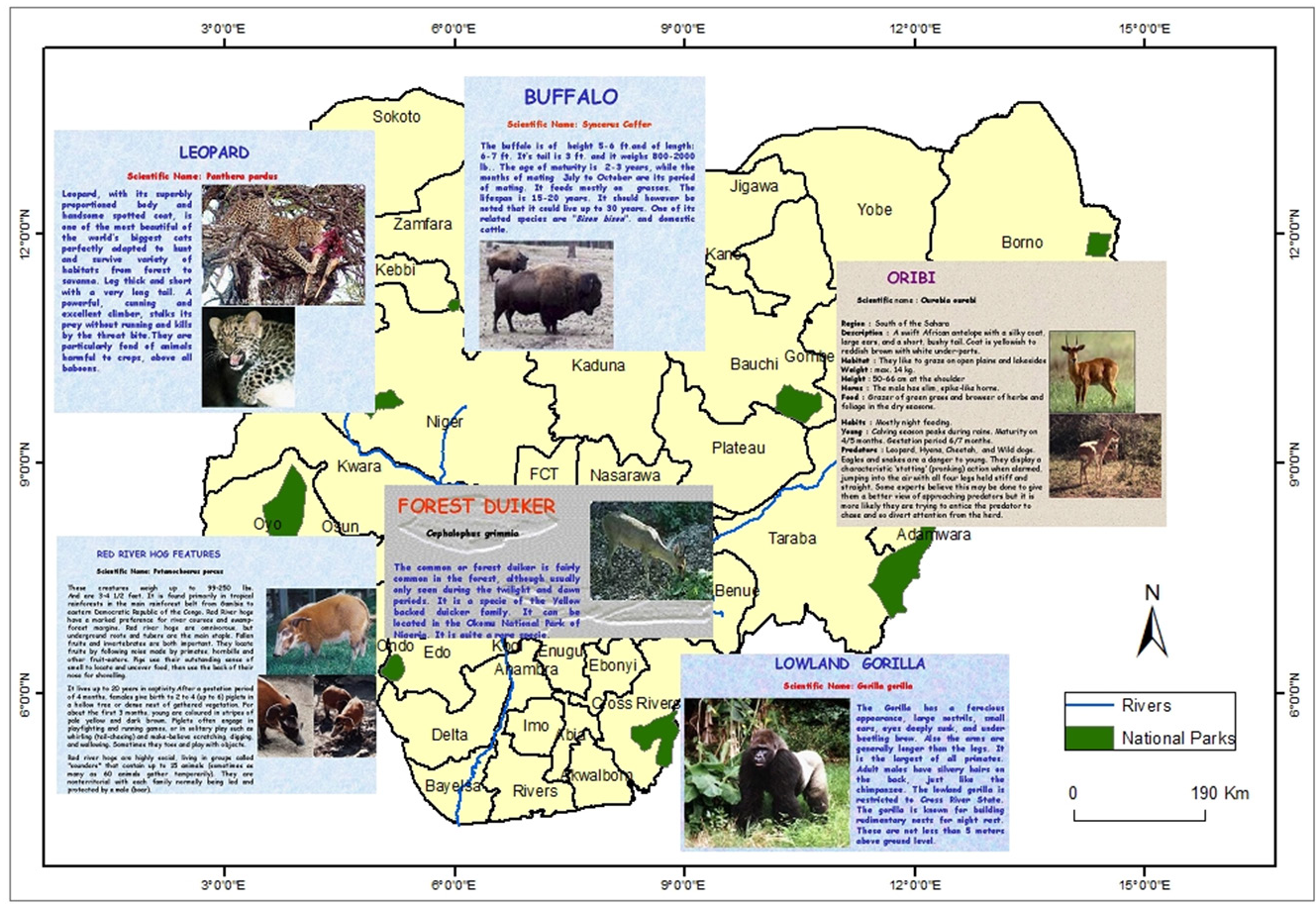

Fig. 6. Map of Nigeria's National Parks hyperlinked with photos and textual information on some wildlife animals found in the parks 
is also contained in the GIS attribute database, was manipulated in GIS environment to produce the map in fig. 5 , which shows the distribution pattern of some wildlife species in the parks.

\subsection{Prospects of multimedia tourism mapping in Nigeria}

Though the present status of tourism mapping in Nigeria leaves much to be desired, it is heartening to note, however, that there are several opportunities for the use of Geoinformation Technologies (GITs) to facilitate and enhance the production, maintenance, distribution and utilization of tourist maps of the country. The availability of the GIT resources proves the viability of extensive and sustainable national tourism mapping in Nigeria powered by modern Science, Technology and Innovation (STI). Some studies carried out have demonstrated the possibility, viability and sustainability of adopting a multimedia cartographic and GIS approach to tourism mapping and development in Nigeria. (See, for example, O.O. Ayeni et al. 2004, O.O. Ayeni 2012, J.C. Ojiako et al. 2015). Below is a brief discussion on some of the existing resources that could be leveraged on to create and maintain Internet-based, GIS-driven multimedia tourism atlas/maps of Nigeria.

\section{The National Space Technology Development policy}

The National Space Research and Development Agency (NARSDA) has initiated a scheme tagged Space Application Support for Sustainable Development (SASSD). Overall, the scheme is designed to use space technology to ensure that development is deliberately and consciously monitored such that the effects of productivity and human activities do not impact negatively on the environment. To this end, a number of projects were identified for implementation. Interestingly, the development of Atlas and Tourist Guides was one of such projects. The project has led to the production and sell of the Abuja Atlas and Tourist Guides. Similarly, the National Centre for Remote Sensing, Jos, has completed a Tourists sites map of Plateau State in the North Central zone of the country. Although the space-based tourism mapping projects are yet to cover the entire country, they nonetheless point to the existing huge prospect

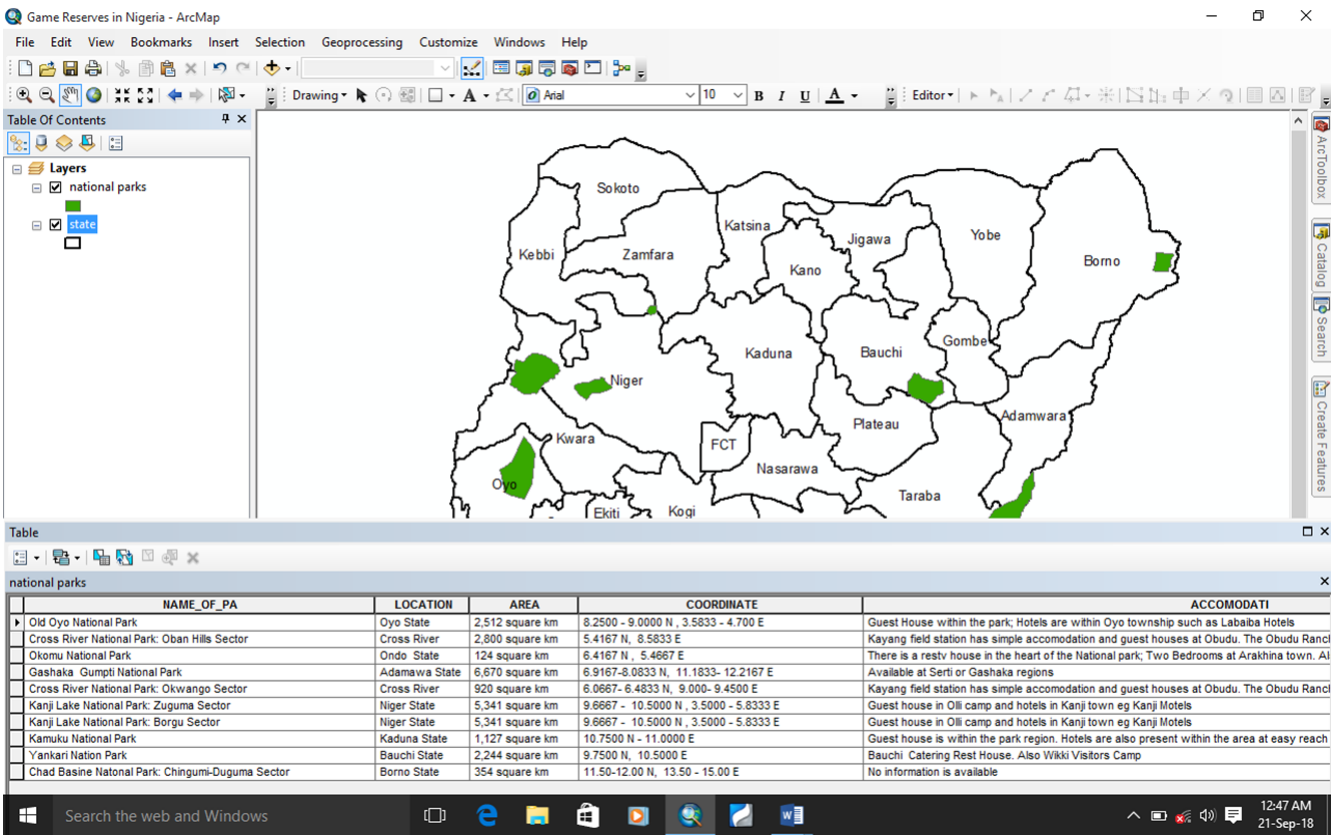

Fig. 7. Screenshot of a GIS map of Nigeria's National Parks hyperlinked with some of their textual attributes 
of using space technology for sustainable development of various tourism maps of the country.

\section{Earth Observation Remote Sensing}

Nigeria is gradually making inroads into space science and technology. Through the remote sensing technique Nigeria has acquired a large collection of aerial photographs and satellite imageries of different resolutions. Thus far, three Nigerian Earth Observation Satellites (EOS) have been successfully launched into outer space orbit. These imaging satellites are NigeriaSat-1, which was launched on 27th September, 2003, and NigeriaSat-2 and NigeriaSat-X, both of which were simultaneously launched on 17th August, 2011. Both NigeriaSat-2 and NigeriaSat-X were built to provide high-resolution satellite images. The Nigerian satellite systems provide primary geospatial datasets, which could be used for different purposes. The NigeriaSat-1 has a 32-metre spatial resolution. Hence, the image data from this satellite is suitable for mapping at medium scales ranging from 1:100,000 to $1: 250,000$ (N.O. Uluocha 2007). On the other hand, the NigeriaSat-2, which is camera-based, has two imagers namely Medium Resolution Imager (MRI) and Very High Resolution Imager (VHRI). The VHRI comprise two modes - the 2.5-metre very high resolution Panchromatic (Pan) mode and the 5-metre high resolution four-band Multi-spectral (MS) mode (Blue, Green, Red, and Near Infra-Red (NIR) bands). The very high resolution images from NigeriaSat-2 are ideal for the production of large scale maps. Like NigeriaSat-2, NigeriaSat- $X$ is also an imaging microsatellite. The NigeriaSat-X sensor has a Ground Sampling Distance (GSD) of $22 \mathrm{~m}$ across a $600 \mathrm{~km}$ swath width; hence it provides $22 \mathrm{~m}$ multi-spectral imagery using the Red (R), Green (G), and Near Infrared (NIR) spectral bands.

Both NigeriaSat-2 and NigeriaSat-X were designed to provide Nigeria with valuable geographically-referenced high-resolution satellite images for applications in mapping, water resources management, agricultural land use, population estimation, health hazard monitoring and disaster mitigation and management, and so on. One of the major objectives of the Nigeria remote sensing satellite systems (NigeriaSat-1, NigeriaSat-2 and NigeriaSat-X) is to support various mapping applications and support development of the National Geospatial Data Infrastructure (NGDI) project. This particular objective makes it mandatory that the satellite systems should provide both medium and high spatial resolution images, which amongst other things, will be quite useful for nationwide tourism mapping.

\section{National Geospatial Data Infrastructure (NGDI) project}

Nigeria has inaugurated a National Geospatial Data Infrastructure (NGDI) project. This followed the enactment of the National Geospatial Information Policy of Nigeria in September 2003. The paper by G.I. Agbaje and J.O. Akinyede (2005) provides an excellent overview of the Geo-Information (GI) Policy of Nigeria. The country's NGDI Project is under the purview of the National Space Research and Development Agency (NASRDA). The main thrusts of the nation's NGDI scheme include the discovery, harmonisation and standardisation of geospatial data production and management, and the provision of a platform for data sharing to eliminate data duplication and also conserve cost and time spent in producing already available data.

In line with the National GI Policy, NASRDA has been collaborating with the Office of the Surveyor-General of the Federation (OSGOF) to provide a network of GPS geodetic controls covering the entire country. Apart from being a fundamental dataset for the NGDI, the establishment of these geodetic controls is essential for the processing of imageries of the NigeriaSat-1, NigeriaSat-2 and NigeriaSat-X to ortho-rectification level. The successful completion of the GPS geodetic controls project will be an essential input into the ongoing plan to density, harmonise and adjust the national geodetic control network as a precursor to an effective NGDI. When completed and fully operational, the NGDI will be a rich source of the relevant basic geospatial data required for, amongst others, the effective and efficient production of tourism maps of the country.

\section{Digital cartography and enterprise Geographic Information Systems (GIS)}

Generally, the adoption and implementation of digital mapping using Geographic Information 
Systems (GIS) is currently on the ascendancy in the country. Various federal government Ministries, Departments and Agencies (MDAs) have installed and are currently using GIS in their daily operations. Similarly, several state governments across the country such as Lagos, Cross River, Ogun, Anambra and so on, including the Federal Capital Territory (Abuja) have established functional enterprise GIS centres. In the same vein, the development of GIS-based application-specific projects by NASRDA is on-going. In order to demonstrate the efficacy of GIS and hence the need for NGDI for efficient planning and good decision making, NASRDA is currently collaborating with some national agencies on NGDI application-specific projects. Without a doubt, the tourism sector stands to gain tremendously from the application of digital cartography and GIS in creating functional Tourist Guide maps and atlas of Nigeria.

Currently, the existing analogue 1:50,000 topographic map series of the country are being converted to digital format by the Office of the Surveyor-General of the Federation (OSGOF). The digitization project is part of the aim to provide a good geodetic and cartographic framework of the country that contains vital geospatial base data, which will form the backbone for various resource mapping and spatial analysis activities. The dataset thus generated will be an essential component of the NGDI, which will be used for various digital mapping operations. Without a doubt, digital mapping will facilitate the identification, design and cartographic rendition of specialized and uncommon maps of major recreation and tourist attractions in the country.

\section{Freedom of Information Act}

The Freedom of Information Act (FOIA) in Nigeria was signed into law on May 28, 2011. In a nutshell, the Act was enacted in the public interest to make public records and information more freely available, provide for public access to public records and information, protect public records, and ease the process of information sharing. Map makers can leverage on the FOIA to request for and obtain useful existing tourism-related data needed for the production of tourism maps.

\section{GPS and other navigational systems}

Global Positioning System (GPS) and other satellite navigation devices are widely used across Nigeria in various military and civil application areas including recreation and tourism. We are currently witnessing the development of Nigeria GPS maps, which can run on a variety of GPS devices. The GPS maps contain tourism-related information on cities, towns, villages, highways, roads, railroads, coastline, national parks/preserves, businesses and some other local points of interest. Various retail outlets in the country stock portable satellite navigation devices with street level 2D and/or 3D maps of some cities in the country. For example, with some of the GPS navigation devices currently available in the country, one can find places of interest on detailed street maps. Important locations like Automated Transaction Machines (ATMs), banks, hotels, bureau de change, police stations, petrol stations, and so on, can easily be located on the map. Moreover, with some of these devices, which also contain travel guide, one can get voice-based turn-by-turn direction to any location found on the map. One can also add to the map by loading one's own customized Points of Interest (POls). Thus, one can now easily undertake a survey with GPS in picking the location of tourism attraction sites within the country. The present widespread availability and use of GPS data will act as a fillip to multimedia tourism mapping in Nigeria.

\section{Cinematography/videography}

Videography and cinematography are concurrently growing by leaps and bounds in $\mathrm{Ni}-$ geria. This is largely made possible by the phenomenal growth of the movie industry in the country, as a result of the exploits of the world acclaimed Nigeria's Nollywood. A good number of the Nollywood movies contain a significant proportion of tourism-related sounds and sites, including traditional practices, songs and dances, cultural festivals, masquerades, breath-taking natural sites, and so on. The feats achieved in the Nollywood film industry can be replicated in producing dedicated high-quality tourism-oriented movie documentaries that will form an integral part of the national digital multimedia, multisensory tourism maps and atlases of Nigeria. 


\section{Geo-Animation}

As earlier indicated, animation is a component of multimedia cartography. Because of their inherent visual appeal, animation and computer games can be effectively harnessed to create functional and efficacious tourist maps. The animation technology is very much in use in Nigeria. For quite a while now, animatronics has been a means of visual communication in the country, especially in the production and use of children's educational material as well as in advertisement of products and services by companies. However, geographical animation (or geo-animation) in particular is not yet widespread. Given the currently available infrastructural resources and technological know-how in the country, the animation technology can be efficiently used to simulate and present various animated renditions of the country's tourism resources.

\section{Unmanned Aerial Vehicles}

Another important development that holds much potential for multimedia tourism mapping in Nigeria is the Unmanned Aerial System (UAS). Nigeria is currently witnessing the gradual but steady introduction and use of UAS or Unmanned Aerial Vehicles (UAVs) otherwise known as drones. Some government agencies, private individuals and corporate entities are now using the drone technology for various purposes such as security, research, education, and so on. Drone activities can sporadically be witnessed across the country's skyscape. Unmanned aircraft have immense potential to assist in tourism mapping. Introducing UAS into tourism mapping could make the entire process to be faster, cheaper and safer. Civilian drones equipped with TV cameras can effectively be used to obtain video images of tourist attractions across the country.

\subsection{Challenges of GIT-based multimedia tourism mapping in Nigeria}

There are some notable challenges that could encumber the attainment of effective and efficient multimedia tourism mapping in Nigeria, if not properly addressed (see also N.O. Uluocha 2001). One major challenge is that tourism mapping is yet to form an integral part of the tourism development Master Plan of the country. The country lacks a distinct policy on tourism mapping. Hence, there is currently no institutional mandate for comprehensive mapping of the country's tourism resources. At best, tourism mapping in the country is often undertaken on ad hoc basis and in piecemeal. This creates a scenario where some areas are intermittently mapped while some others are not. The general apathy towards tourism mapping is perhaps owing to insufficient awareness of the strategic role of maps in tourism planning, development, promotion and management.

Another challenge is the fact that currently, Nigeria does not have a comprehensive, geographically-referenced nationwide database of all the extant tourism attractions and their attributes. This challenge is further exacerbated by the fact that data sharing is still problematic. Various public and private organisations/institutions are not so accustomed to working in synergy; hence, they are often reluctant to share data. Moreover, data created for an application may not be easily translated into another application due to lack of interoperability between systems. Non-availability of metadata (i.e. information about data on 'who owns what, when, where, and how'), equally inhibits data sharing among organisations/institutions; and this leads to loss of millions of dollars on reproducing/duplicating already existing data (G.I. Agbaje and J.O. Akinyede 2005). The non-existence of a robust National Tourism Information System (NTIS) could pose a significant threat to the success of a national multimedia tourism mapping project.

Shortage of funding is one other potential obstacle to achieving effective sustainable multimedia tourism mapping in Nigeria. Generally, the annual budgetary allocation for mapping by both the federal and state governments is usually quite paltry. And since tourism mapping in particular is hardly on the priority list, there is always little or no funds for financing tourism mapping projects. On the other hand, private or corporate entities who are usually profit-oriented are yet to discover and harness the commercial values and economic potentials of tourist maps. The present underdeveloped and uninspiring state of the tourism industry in Nigeria does not quite stimulate the interest of potential investors, who, in turn, could spearhead the production and distribution of high quality tourist maps of the country. 


\subsection{A multimedia tourism mapping system}

Adopting a multimedia, multisensory cartographic approach will definitely reposition the mapping and promotion of Nigeria's tourism assets. Figure 8 is a schematic diagram of a multimedia tourism mapping system that could be adopted to improve effective and efficient tourism mapping of the country. Each component of the system is briefly explained below.

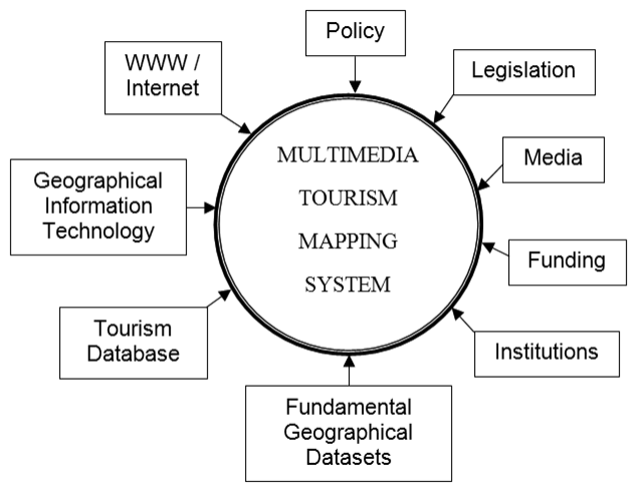

Fig. 8. Components of a multimedia tourism mapping system

Policy: The formulation and implementation of an appropriate national tourism mapping policy and Master Plan is a sine qua non for effective and sustainable multimedia tourism mapping.

Legislation: When formulated, the national tourism mapping policy must be backed with an enabling legal framework.

Media: As already identified, the multimedia tourism atlas/maps to be produced will consists of the integration of maps with other relevant communication media including speech/sound, static photos, video images, and animations.

Funding: Adequate funding is necessary for national mapping agencies and other geospatial data service providers to be able to procure and use modern cost-effective and time-saving technologies for data acquisition, processing and mapping.

Institutions: The appropriate institutions that would be directly or indirectly involved in the planning, implementation and management of the national multimedia tourism mapping project must be clearly identified. Such institutions may include (but not limited to) the Nigerian Cartographic Association (NCA), the National Tourism Development Corporation (NTDC), National Space Research and Development Agency (NASRDA), and the Office of the Surveyor-General of the Federation (OSGoF). The institutions must work in synergy to achieve the set mandate.

Fundamental geographical dataset: A good geodetic and cartographic framework of the country that contains vital geospatial base data is essential to the implementation of the multimedia tourism mapping project. The base data, which will comprise administrative boundaries (both local and international), graticules, major rivers and other water bodies, etc., will form the backbone for various tourism resources mapping and spatial analysis activities.

Tourism database: The tourism database will provide current, accurate and comprehensive geospatial and attribute information about all the natural and cultural (man-made) tourist attractions in the country. In addition, the tourism database will contain vital details about ancillary, tourism-related facilities and services such as transportation, hotel accommodation, restaurants, entertainment centres, shopping centres, banking facilities, security units, and so on.

Geoinformation and allied technologies: Effective planning, execution and management of the tourism mapping project will definitely require the full complements and deployment of geoinformation and allied technologies, including digital cartography, remote sensing, computer graphics, GIS, GPS, videography, animatronics, photography, ICT, and so on.

Internet: The Nigeria multimedia tourism mapping scheme is envisaged to be Internet-based. This is important to make the maps easily visible and accessible to the global audience. However, making the maps available on the Internet does not preclude the possible production of the analogue (hard copy) versions of the maps.

\section{Recommendations}

Nigeria has much of the resources she needs to create and maintain GIT-based, Internet-compatible multimedia/multisensory tourism atlas and tourist guides. What is largely missing is the much-needed policy guideline for an integrated and coordinated approach to tourism 
mapping in the country. Achieving effective tourism mapping requires both conscious and conscientious efforts. Of course, this presupposes the existence of a well thought-out and all-embracing tourism development Master Plan coupled with a clear-cut mandate to execute the plan. The production of Guide Maps for publicizing and promoting Nigeria's tourism endowments must be made a specific cardinal objective of the Nigerian Tourism Development Corporation (NTDC).

The government of Nigeria must ensure that all the necessary infrastructure for tourism development and promotion is in place. To this end, in addition to the existing machineries, the country needs to formulate a robust, innovative and sustainable national tourism mapping policy. It is quite imperative for the NTDC to draft and implement a detailed multimedia tourism mapping blueprint for the country which emphasizes the use of digital geoinformation techniques in the mapping effort. The challenge of geospatial data incompatibility and sharing, as identified earlier, can be resolved by fully implementing the NGDI and systems (e.g. OpenGISConsortium) that will ensure interoperability between systems. Apart from the provision of an enabling tourism mapping policy instrument, another issue that government must take urgent steps to address is the shortage of funds for national mapping. The annual fiscal allocation to mapping needs to be significantly improved upon for any meaningful results to be achieved.

Besides, a comprehensive inventory of the nation's tourism resources needs to be undertaken. Arising from such inventory, an all-inclusive geographically-referenced tourism database of the country should be created and maintained. Nigeria needs to create an electronic National Tourism Information System (NTIS), which can effectively and efficiently be used in conjunction with the NGDI to produce automated national tourism atlases and maps.

Tourism marketing in Nigeria must be rebranded. More emphasis needs to be placed on advertising domestic tourism assets to the global community. An undisputable tool for effective and efficient marketing of Nigeria's tourism resources is Internet-based multimedia tourism atlases/maps of the country. More so, there is need to woo potential investors to the tourism sector. The private sector needs to be fully involved in the use of geoinformation tech- nologies in producing multimedia tourism maps of the country. The government also needs to take pragmatic steps to create a safe and enabling environment for investors to come in and do business in the country. Undue official bureaucracy makes it stressful for investors or travelers to Nigeria to do so with ease. Therefore, government needs to cut back on bureaucracy to ensure that travelers to the country, especially international tourists, can do so easily and with the least amount of stress.

\section{Conclusion}

Nigeria is endowed with a lot of tourism potentials which could be developed and harnessed for economic prosperity. Despite the huge tourism potentials in the country, however, the country's tourism industry is currently underperforming. Improving the abysmal performance of the country's tourism sector would require aggressive and proper mapping and marketing of the sector. Maps are essential to tourism industry development and management. Mapping holds the key to a positive turnaround in the country's quest to make tourism a major source of revenue. Nonetheless, to achieve effective creation, distribution and use of tourist maps of the country, a more pragmatic and modern technology-based method must be adopted. More specifically, a Geoinformation Technology-based approach to multimedia tourism mapping for sustainable tourism growth and development in Nigeria holds the prospects for vastly improved tourism mapping in the country.

If the current challenges of tourism mapping in Nigeria are promptly and properly addressed, efficient, robust and comprehensive tourism mapping of the nation's tourist attractions will be easily achieved. The resources needed for effective and sustainable Internet-based multimedia tourism mapping of Nigeria's tourism attractions are largely available. They only need to be properly coordinated and harnessed. This would require conscious and concerted effort on the part of the government and other relevant stakeholders in the tourism industry to embrace and mainstream tourism mapping in every tourism development blueprint. No effort should be spared at vigorous mapping, packaging and promoting tourism in Nigeria in order to create a major traffic to the country's different tourist destinations. 


\section{Literature}

Agbaje G.I., Akinyede J.O., 2005, NGDI Development in Nigeria: Policy Issues on Information Access and Information Dissemination. "United Nations Economic Commission for Africa CODI-IV", April 23-28, 2005.

Akukwe T.I., Odum C.J., 2014, Designing and Developing a GIS Database for Tourism in Nigeria: The Case of Anambra State. "IOSR Journal of Humanities and Social Science (IOSR-JHSS)" Vol. 19, Issue 10, Ver. VIII, pp. 109-120 e-ISSN: 2279-0837, p-ISSN: 2279-0845. www.iosrjournals.org (Retrieved 2 May, 2018).

Ayeni O.O., Saka D.N., Yakubu N., 2004, Application of Multimedia GIS to Tourism in Abuja and Environs. In: P.C. Nwilo, N.O. Uluocha, D.N. Saka (eds.), Application of Geoinformation to the Development and Management of Nigeria's Resources, Lagos: Geoinformation Society of Nigeria, pp. 103-113.

Ayeni O.O., 2012, A Multimedia GIS Database for Planning, Management and Promotion of Sustainable Tourism Industry in Nigeria. In: B. Ayeni, O. Fabiyi (eds.), Geospatial Technologies and Digital Cartography for National Security, Tourism and Disaster Management, Proceedings of Joint Conference of Geoinformation Society of Nigeria \& Nigerian Cartographic Association.

Castaldini D., 2008, Maps and Multimedia Tool for the Environmental Tourism in Protected Areas of the Modena Apennines (Northern Italy). "GeoJournal of Tourism and Geosites" Vol. I, no. 1, pp. 13-33.

Eboy O.V., 2017, Tourism Mapping: An Overview of Cartography and the Use of GIS. "BIMP-EAGA Journal for Sustainable Tourism Development" Vol. 6, no. 1, pp. 61-67.
Kraak M.J., Ormeling F.J., 1998, Cartography: Visualization of Spatial Data. Singapore: Addison Wesley Longman, Pte Ltd.

Ojiako J.C., Sagir M., Igbokwe E.C., 2015, Location and Spatial Analysis of Tourism Facilities in Abuja Municipal Area Council, FCT, Nigeria Using GIS Approach. "International Journal of Scientific \& Engineering Research" Vol. 6, issue 5, pp. 467-475.

Peterson M.P., 1999, Elements of Multimedia Cartography. In: W. Cartwright, M.P. Peterson, G. Gartner (eds.), Multimedia Cartography. New York: Springer.

Ufuah M.E., 2006, Contemporary Methods in Cartography. Benin City: Ever-blessed Publishers.

Uluocha N.O., 2001, Appraisal of Tourist Mapping in Nigeria. In: Proceedings of the 2001 International Cartographic Association (ICA) Conference, Beijing, China. Available at icaci.org/documents/ICC_ proceedings/ICC2001/icc2001/file/f09002.doc (Retrieved 5/5/18).

Uluocha N.O., 2004, Mapping and Managing Wildlife Parks in Nigeria: a GIS Approach. In: P.C. Nwilo, N.O. Uluocha, D.N. Saka (eds.), Application of Geoinformation to the Development and Management of Nigeria's Resources. Lagos: Geoinformation Society of Nigeria, pp. 89-102.

Uluocha N.O., 2007, An Overview of the Cartographic Utility of NigeraSat-1 Images. In: D.A. Musa, W.D.C. Wokoma (eds.), Achieving Development Goals through Mapping. Lagos: Nigerian Cartographic Association, pp. 102-119.

Uluocha N.O., 2012, Fifty Years of Post-Colonial Mapping in Nigeria: An Overview. "Cartographica" Vol. 47, no. 3, pp. 179-194. 